The Historical Austen 
This page intentionally left blank 


\section{The Historical Austen}

\section{William H. Galperin}

\section{PENN}

University of Pennsylvania Press

Philadelphia 
Copyright 12003 University of Pennsylvania Press

All rights reserved

Printed in the United States of America on acid-free paper

$\begin{array}{llllllllll}10 & 9 & 8 & 7 & 6 & 5 & 4 & 3 & 2 & 1\end{array}$

First paperback edition 2005

Published by

University of Pennsylvania Press

Philadelphia, Pennsylvania 19104-4112

Library of Congress Cataloging-in-Publication Data

Galperin, William $H$.

The historical Austen / William H. Galperin.

p. $\mathrm{cm}$.

Includes bibliographical references and index.

ISBN o-8122-3687-4 (acid-free paper). — ISBN o-8122-1924-4 (pbk. : alk. paper)

1. Austen, Jane, 1775-1817-Criticism and interpretation-History. 2. Literature and historyGreat Britain-History-19th century. 3. Women and literature-England-History-19th century. 4. Austen, Jane, 1775-1817-Knowledge-History. I. Title.

PR4037. G35 2002

$823 \cdot 7-\mathrm{d}$ - $c 21$ 
For my aunt, Rae Fixel, reader par excellence 
This page intentionally left blank 